\title{
Three-Dimensional Stability Analysis of a Homogeneous Slope Reinforced with Micropiles
}

\author{
Shu-Wei Sun, Wei Wang, and Fu Zhao \\ Faculty of Resources and Safety Engineering, China University of Mining and Technology, Beijing 100083, China \\ Correspondence should be addressed to Shu-Wei Sun; ssw1216@163.com
}

Received 12 August 2014; Accepted 30 September 2014; Published 21 October 2014

Academic Editor: Evangelos J. Sapountzakis

Copyright ( 2014 Shu-Wei Sun et al. This is an open access article distributed under the Creative Commons Attribution License, which permits unrestricted use, distribution, and reproduction in any medium, provided the original work is properly cited.

\begin{abstract}
Micropiles are widely used to reinforce slopes due to their successful performance and fast construction. In this study, a simple nonlinear method is proposed to analyze the stability of a homogeneous slope reinforced with micropiles. This method is based on shear strength reduction technique, in which the soil behavior is described using the nonassociated Mohr-Coulomb criterion and micropiles are modeled as 3D pile elements. A series of slope stability analyses is performed to investigate the coupled mechanism of micropile system, and the optimum of pile position, depth of embedment, and length of truncation are analyzed. Results show that the position of micropile system plays an important role not only in the calculation of the safety factor, but also in locating the failure surface, which demonstrates the dominating coupled effect exists between micropiles and slope. The critical embedment depth of the micropile is about 2 times the length of micropile above the critical slip surface, and the micropiles flexure rather than rotation becomes increasingly prevalent as the depth of micropiles embedment increases. Truncation of micropiles may improve the capacity of the micropile system, and the largest truncation length of micropile is about 1/4 depth of critical slip surface in this study.
\end{abstract}

\section{Introduction}

The use of micropiles to stabilize an unstable slope has been widely adopted in recent years (e.g., [1-6]). A micropile is a small-diameter (typically less than $300 \mathrm{~mm}$ ), drilled, and grouted nondisplacement pile that is typically reinforced. Micropiles can withstand relatively significant axial loads and moderate lateral loads and can be constructed in almost any type of soil/rock conditions. Compared to conventional antisliding piles, micropiles construction is relatively simple, fast, environmental-friendly, and economic. Besides, micropiles can be easily installed in areas with limited equipment access, such as for landslides located in steep, hilly, or mountainous areas (see Figure 1). Drilled micropiles can also be combined with other slope-stabilization techniques, such as retaining wall and use of ground anchors.

Different methods have been used to evaluate the performance and design of the micropiles which are used as reinforcement in slopes. Lizzi [1] suggests that micropiles can be used as the reticulated network system, which creates a stable reinforced soil as "gravity-retaining wall," and the reinforced soil gravity mass supplies the essential lateral loads due to the movement of the unstable slope. Reese el al. [7] described a procedure for the calculating of the resistance provided by micropiles, assuming that the limit state is the failure of the micropile in bending. Loehr et al. [4] also proposed a simplified method for predicting the limit resistance of recycled plastic reinforcement for application to stabilization of minor slopes. In their method, two failure mechanisms are considered to determine the distribution of limit lateral resistance along the reinforcing members: failure of soil around or between reinforcing members and structural failure of the reinforcing member due to mobilized forces from the surrounding soil. The comparative tests between micropiles and conventional antisliding piles conducted by Sun et al. [8] showed that micropiles were totally different from antisliding pile in loading mechanism. Therefore, the solution for conventional piles cannot be easily adapted for the situation of micropiles. Sun et al. [9] developed a limit equilibrium approach for the design of micropiles, and 


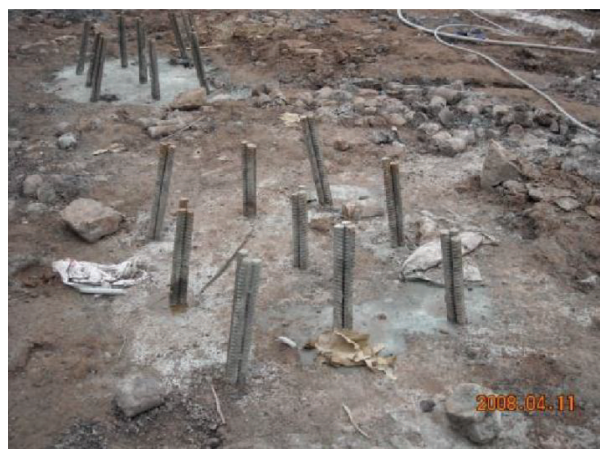

(a)

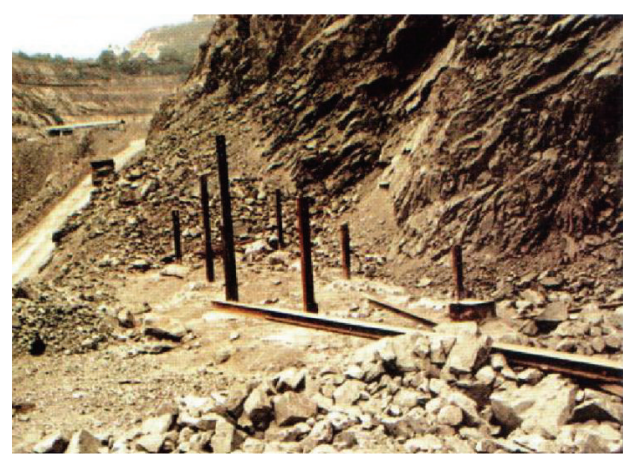

(b)

FIgURE 1: Micropiles for slope stabilization.

the design procedure includes (1) choosing a location for the micropiles within the existing slope; (2) selecting micropile cross section; (3) estimating the length of the micropile; (4) evaluating the shear capacity of the micropiles group; (5) calculating the spacing required to provide force to stabilize the slope; and (6) the design of the concrete cap beam.

Esmaeili et al. [6] presented three experimental models of embankments of $10 \mathrm{~m}$ in height on a scale of $1 / 20$ to set up a number of loading tests. For comparison, three numerical models were developed by using the PLAXIS-3D code based on the FEM. Sensitivity analysis on the geometric parameters of micropiles was conducted to investigate the number, spacing, diameter, and length with the embankment safety factor. It was shown that, with the optimum arrangement of the micropiles, the safety factor of the slope stability and static load-bearing capacity of the embankments will increase by more than 30 and 65\%, respectively; and also the settlement of the embankment crest will decrease by approximately $35 \%$. Isam et al. [10] presented a numerical method for the analysis of inclined micropiles. In this method, the micropiles are modeled as $3 \mathrm{D}$ elastic beam elements, rigidly connected to a cap, which is free of contact with the soil. Then it is showed that the inclination of micropiles leads to a good mobilization of their axial component and consequently to an important decrease in the shearing and bending loading. In general, the soil-pile interaction for such micropiles is very complex and there are many factors whose influence on the final behavior of the structure cannot be conveniently assessed. Thus, a further study of the behavior of micropiled-reinforced slopes is necessary.

The shear strength reduction technique has been used in the stability analysis of slopes without piles by Zienkiewicz et al. [11], Matsui and San [12], Ugai and Leshchinsky [13], Dawson et al. [14], Griffiths and lane [15], Won et al. [16], Lin and Cao [17], and others. For piled reinforced slopes, Wei and Cheng [18] have considered the effects of piles on the stability of a slope by a three-dimensional finite element analysis using the shear strength reduction technique. Won et al. [16] and Cai and Ugai [19] have analyzed the same slope by Wei and Cheng [18]. In the piled slope analysis by Won et al. [16] and Wei and Cheng [18], the location of the critical slip surface was determined by the maximum shear force in the pile so

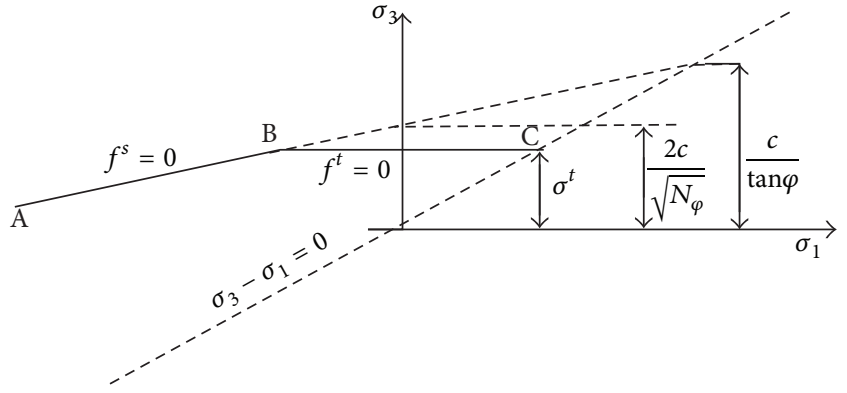

Figure 2: Composite Mohr-Coulomb failure criterion.

that a very deep critical slip surface was determined while the maximum shear strain in the soil was not considered. Cai and Ugai [19] have discussed the use of maximum shear strain and maximum shear strain rate to determine a more realistic critical slip surface.

In this paper, an analytical model is developed to calculate the safety factor of a slope reinforced with micropiles based on the shear strength reduction method. The homogeneous slope considered by Won et al. [16] and Wei and Cheng [18] and Cai and Ugai [19] is employed for the analysis. The soil behavior is described using the nonassociated MohrCoulomb criterion and micropiles are modeled as 3D pile elements. As such, a series of slope stability analyses is performed, and the optimization of pile position, depth of embedment, and length of truncation are discussed.

\section{Analysis Method}

2.1. Model of Materials. In the present study, the soil material of the slope is simulated with an elastic perfectly plastic model, with Young's modulus being $E_{s}$ before yielding. The yielding is described by a composite Mohr-Coulomb criterion with a tension cutoff as shown in Figure 2.

The failure envelope from point $A$ to $B$ is defined by the Mohr-Coulomb criterion $f^{\mathcal{s}}=0$ with

$$
f^{\mathcal{s}}=\sigma_{1}-\sigma_{3} N_{\varphi}+2 c \sqrt{N_{\varphi}}
$$




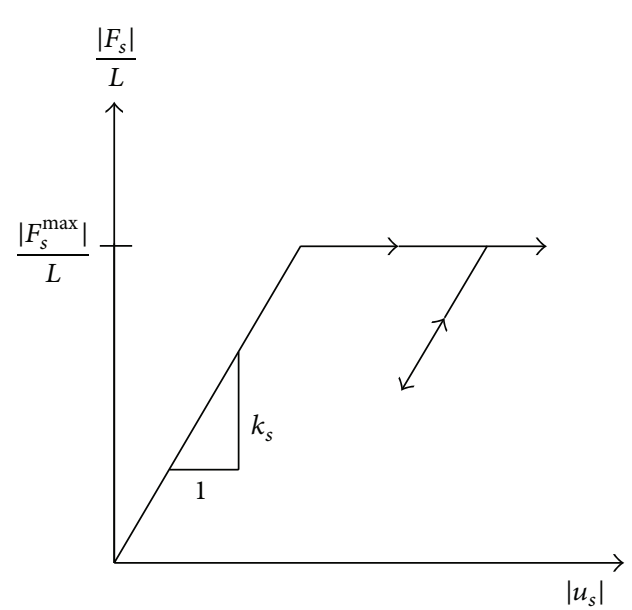

(a) Shear force/length versus relative shear displacement, $u_{s}$

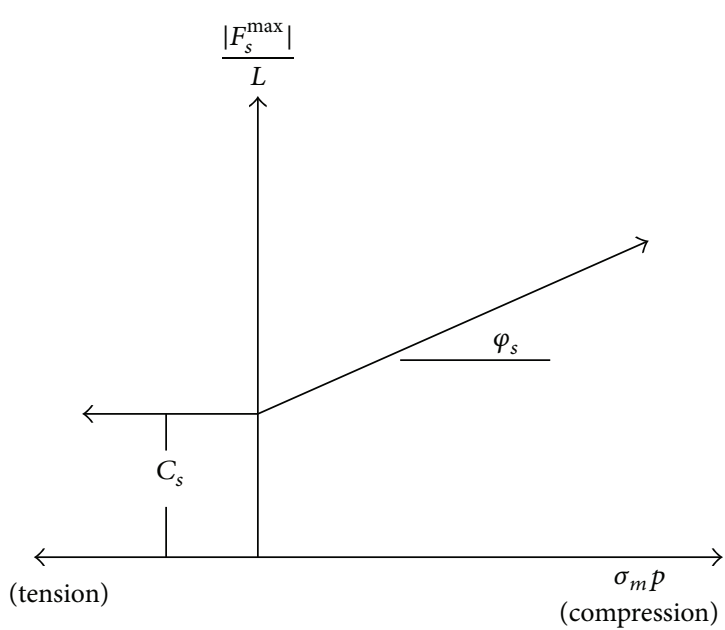

(b) Shear strength criterion

FIGURE 3: Shear-directional material behavior for pile elements.

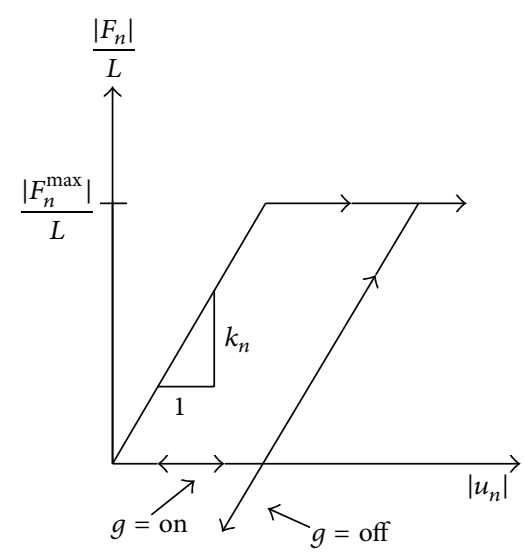

(a) Normal force/length versus relative normal displacement, $u_{n}$

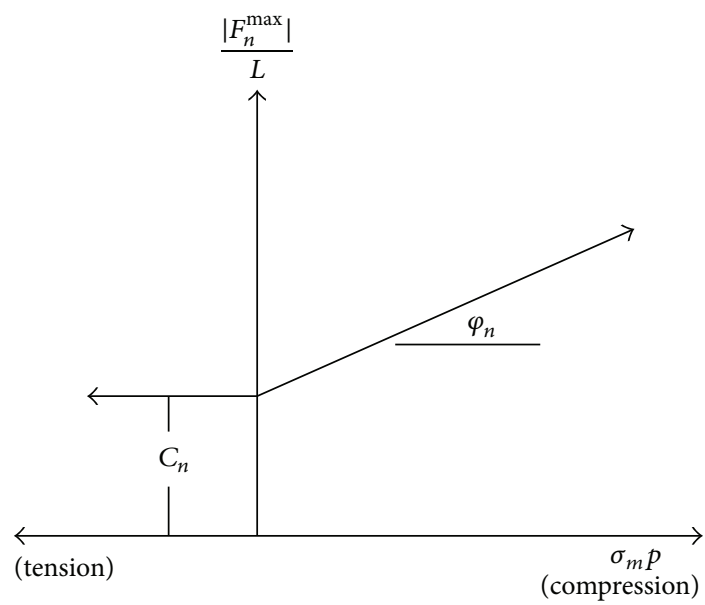

(b) Normal-strength criterion

FIGURE 4: Normal-directional material behavior for pile elements.

where $\sigma_{1}$ and $\sigma_{3}=$ major and minor principal effective stresses, respectively; $c=$ effective cohesion of soil; $\varphi=$ internal friction angle of soil; and $N_{\varphi}=$ function of $\varphi$ :

$$
N_{\varphi}=\frac{1+\sin \varphi}{1-\sin \varphi}
$$

The failure envelope from point $B$ to $C$ is represented by the tension failure criterion of the form $f^{t}=0$ with

$$
f^{t}=\sigma_{3}-\sigma^{t}
$$

where $\sigma^{t}=$ effective tensile strength whose maximum value $\sigma_{\max }^{t}$ is given by

$$
\sigma_{\max }^{t}=\frac{c}{\tan \varphi} .
$$

A "pile" element is used to simulate a micropile behavior. The "pile" element offers the combination features of beam and cable. In this sense, the "pile" element can simulate the combination of tension, shearing, and bending behavior of micropiles. Piles interact with the grid through shear and normal coupling springs which are cohesive and frictional in nature as well as nonlinear.

The mechanical characteristics of shear and normal coupling springs are shown in Figures 3 and 4, respectively, which are located at the nodal points along the pile axis to describe relative shear and normal displacement between the pile/grout interface and the grout/rock interface. These springs present numerically as spring-slider connecters, transferring forces and motion between the pile and the grid at the pile nodes. The shear behavior of the micropilegrid interface during relative shear displacement $u_{s}$ between 
the micropile and the soil is described numerically by the shear coupling spring properties of stiffness $k_{s}$, cohesive strength $C_{s}$, friction angle $\varphi_{s}$, and exposed perimeter $p$. The normal behavior of the micropile-grid interface during relative normal displacement $u_{n}$ between the micropile and the soil is described by the normal coupling spring properties of stiffness $k_{n}$, cohesive strength $C_{n}$, friction angle $\varphi_{s}$, exposed perimeter $p$, and gap-use flag $g$.

2.2. Determination of the Factor of Safety. For slopes, the factor of safety (FS) often is defined as the ratio of the actual shear strength to the minimum shear strength required to prevent failure. A logical way to compute the factor of safety with a finite element or finite difference program is to reduce the shear strength until collapse occurs. The factor of safety is the ratio of the rock's actual strength to the reduced shear strength at failure. This shear strength reduction technique was used first with finite elements by Zienkiewicz et al. [11] to compute the safety factor of a slope composed of multiple materials.

The shear strength reduction technique has two main advantages over limit equilibrium slope stability analyses. First, the critical slide surface is found automatically, and it is not necessary to specify the shape of the slide surface (e.g., circular, log spiral, and piecewise linear) in advance. In general, the failure surface geometry for slopes is more complex than simple circles or segmented surfaces. Second, numerical methods automatically satisfy translational and rotational equilibrium, whereas not all limit equilibrium methods do satisfy equilibrium. Consequently, the shear strength reduction technique usually will determine a safety factor equal to or slightly less than limit equilibrium methods.

To perform slope stability analysis with the shear strength reduction technique, a series of stability analyses are performed with the reduced shear strength parameters $c^{\text {trial }}$ and $\varphi^{\text {trial }}$ defined as follows:

$$
c^{\text {trial }}=\frac{1}{F^{\text {trial }}} c, \quad \varphi^{\text {trial }}=\frac{1}{F^{\text {trial }}} \varphi,
$$

where $c$ and $\varphi$ are real shear strength parameters and $F^{\text {trial }}$ is a trial factor of safety.

Figure 5 shows the proposed analytical model to calculate safety factor of slopes reinforced with micropiles. In Figure 5, the initial $F^{\text {trial }}$ is set to be 1.0 so as to judge the stability of the system. Then the value of $F^{\text {trial }}$ is increased or decreased until the slope fails. After the slope fails, the $F^{\text {up }}$ or $F^{\text {low }}$ is replaced by the previous $F^{\text {trial }}$. Next, a point midway between the upper and lower brackets is tests. If the simulation converges, the upper bracket is replaced. The process is repeated until the difference between upper and lower brackets is less than a specified tolerance $\varepsilon$.

There are several possible definitions of failure, for example, some test of bulging of the slope profile [20], limiting of the shear stresses on the potential failure surface [21], or nonconvergence of the solution [22]. These are discussed in Abramson et al. [23] but without resolution. In this study, the nonconvergence option is taken as being a suitable indicator of failure.
2.3. Method Execution. The proposed method was executed by using a three-dimensional explicit-finite difference program FLAC3D [24], which is a three-dimensional explicit finite-difference program that has the ability to simulate the behavior of soil, rock, or other materials that may undergo plastic flow when their yield limits are reached. The explicit Lagrangian calculation scheme and the mixeddiscretization zoning technique used in FLAC3D facilitate accurate modeling of plastic collapse and flow. The explicit Lagrangian solution scheme involves a large number of calculation steps, each progressively redistributing through the mesh the unbalanced force resulting from changes to the stresses or boundary displacements.

The convergence criterion for FLAC3D is the ratio defined to be the maximum unbalanced force magnitude for all the gridpoints in the model divided by the average applied force magnitude for all the gridpoints. The maximum unbalanced force is the magnitude of the vector sum of nodal forces for all of the nodes within the mesh. The model is considered to be in equilibrium when the maximum unbalanced force is small in comparison with the total of the applied forces associated with stress or boundary displacement changes. If the unbalanced force approaches a constant nonzero value, this usually indicates that failure and plastic flow are occurring within the model. The model is normally assumed to be in equilibrium when the maximum unbalanced force ratio is below $1 \times 10^{-5}$.

\section{Validation and Application of the Method}

Wei and Cheng [18] performed a numerical analysis to investigate the effect of stabilizing piles on the stability of a slope. For the slope as shown in Figure 6, it is $10 \mathrm{~m}$ in height with a gradient of $1 \mathrm{~V}: 1.5 \mathrm{H}$ and a ground thickness of $10 \mathrm{~m}$. The material properties for prediction purposes were selected based on Cai and Ugai's assumptions and the cohesive strength, friction angle, elastic modulus, Poisson ratio, and unit weight of the soil are $10 \mathrm{kPa}, 20^{\circ}, 200 \mathrm{MPa}$, 0.25 , and $20 \mathrm{kN} / \mathrm{m}^{3}$, respectively. Two symmetric boundaries are used and nodes on the symmetric faces were prevented from moving in the $y$-direction, but free to move in the $x$ - and $z$-directions. The nodes on the right- and left-hand faces were restrained from moving in the $x$-direction while both horizontal and vertical displacements are fixed along the bottom boundary.

The factor of safety of the slope is 1.16 using the proposed method with program FLAC3D, and the critical slip surface is shown in Figure 7. Cai and Ugai [19] have discussed that the use of maximum shear strain and maximum shear strain rate in the nonlinear iteration will give virtually the same result in most cases, and the adoption of the maximum shear strain in the present study is in line with the flow rule relation. The Cai and Ugai's shear strength finite element method and the Bishop's simplified method gave safety factors of 1.14 and 1.13 , respectively. It should be noted that the final calculated factor of safety by finite difference methods depends highly on the size of element unlike finite element methods in which a shape function can be used within the elements. In general, 


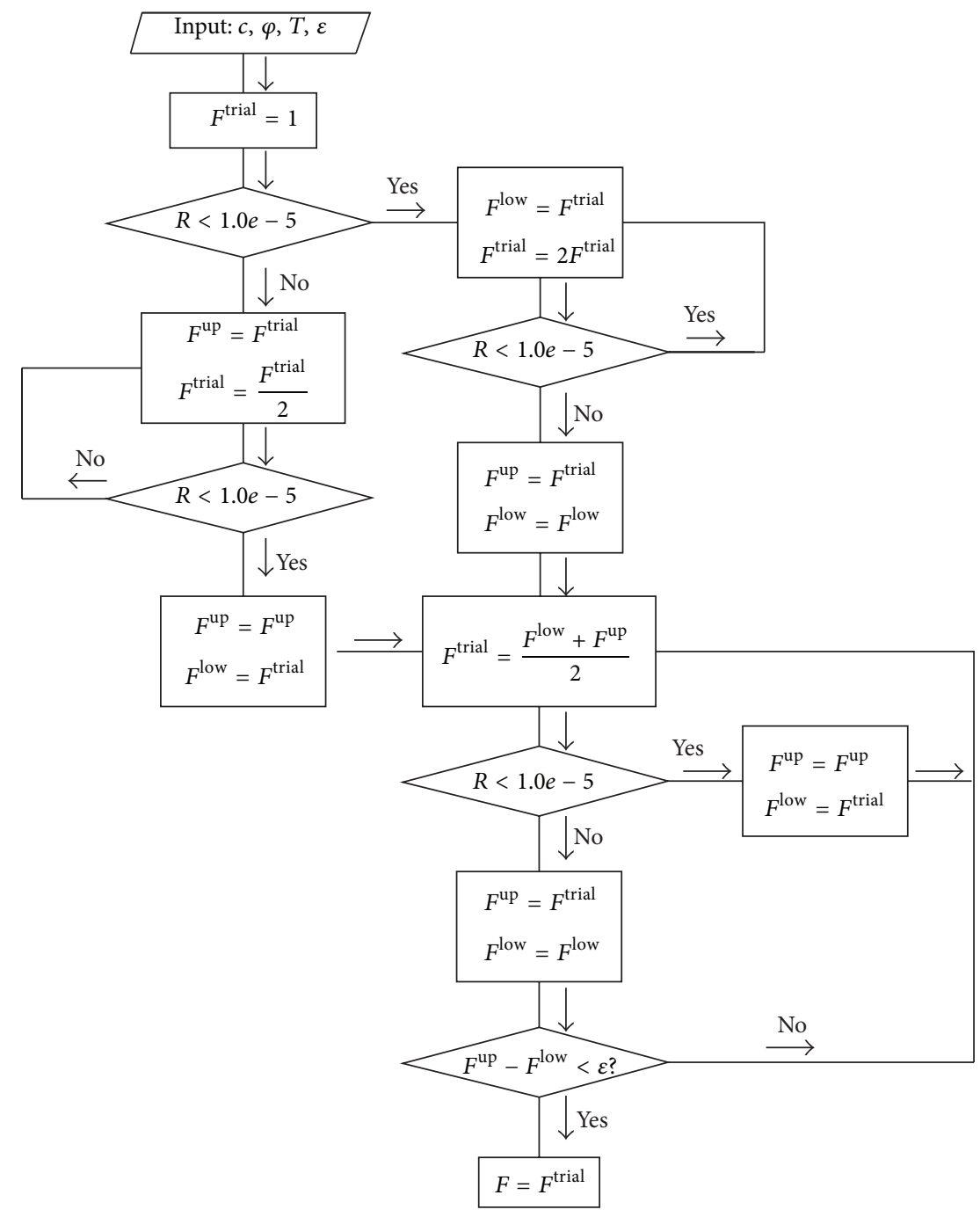

Figure 5: Analytical model for obtaining the $F_{s}$ of the reinforced slope.

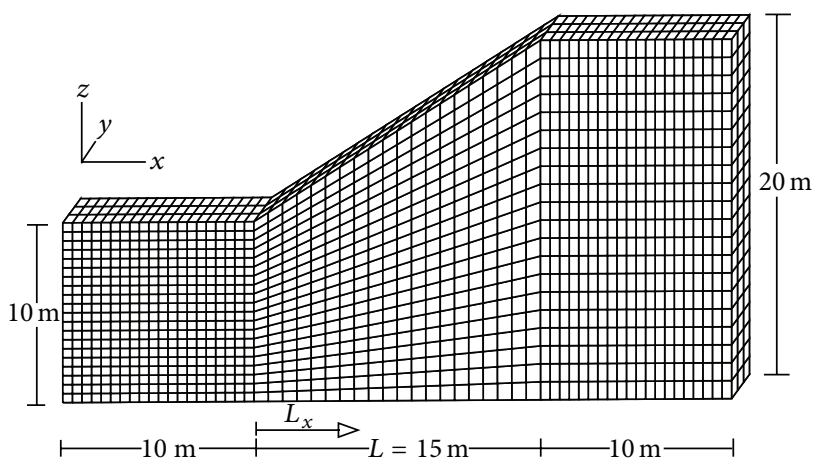

FIGURE 6: Slope model and finite difference mesh.

the finer the size of element is, the more precise the result is. So, the authors view that the factor of 1.16 is a slightly better result for the present problem. Thus, the overall model performance in predicting the factor of safety of the slope is quite satisfactory, adding to confidence in its validity.

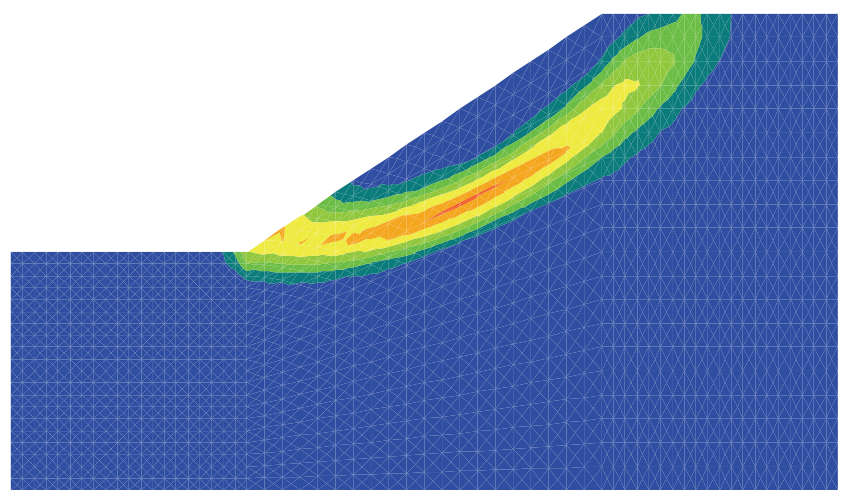

FiguRE 7: Slip surface of the slope $\left(F_{s}=1.16\right)$.

Four steel tube micropiles with an outer diameter of $D=0.15 \mathrm{~m}$ cover a group in slope stabilization as shown in Figure 8. The micropiles are installed in the middle of the slope, that is, the horizontal distance between the slope toe 


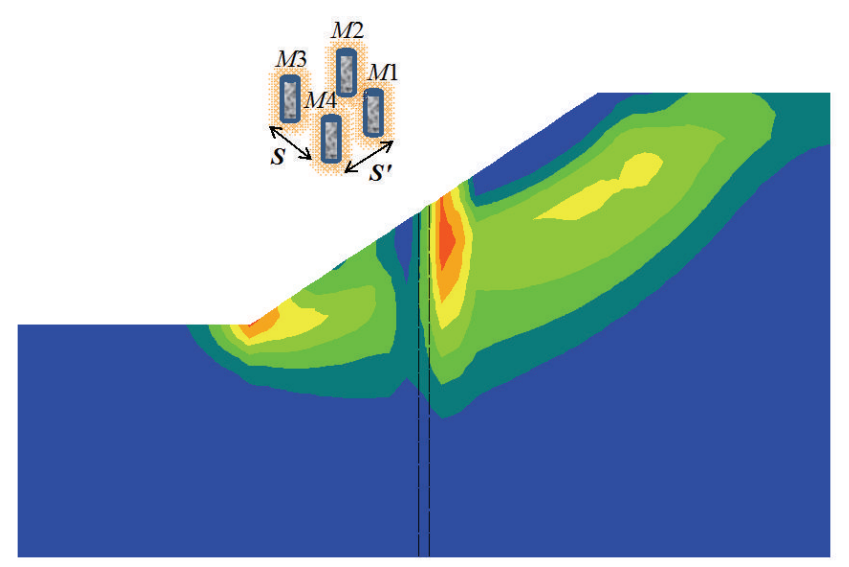

FIGURE 8: Slip surface of the reinforced slope $\left(F_{s}=1.45\right)$.

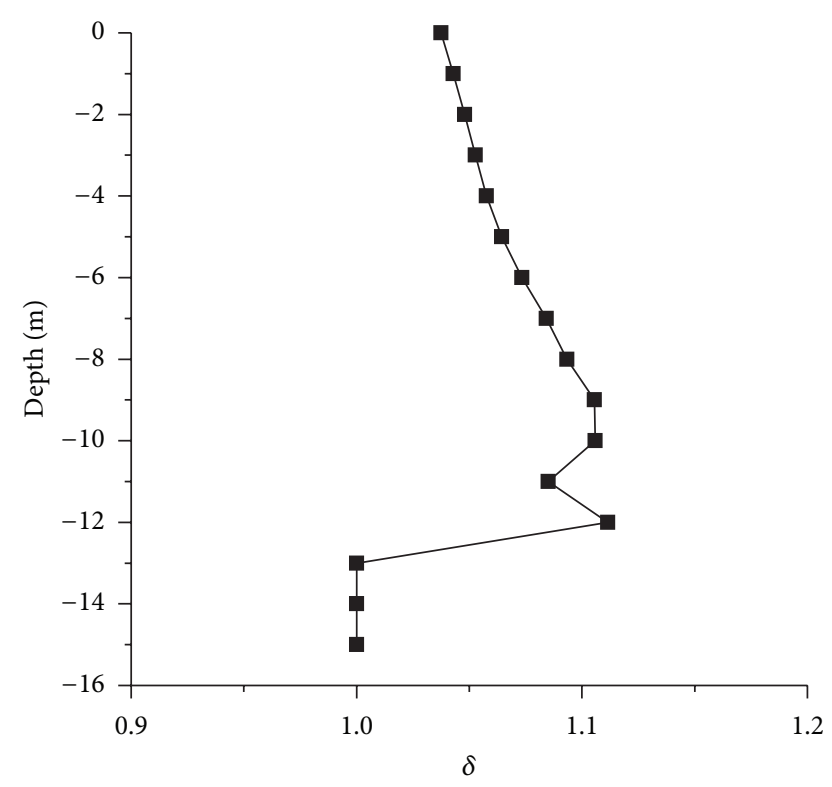

FIgURE 9: Values of $\delta$ for different depth.

and the pile position $L_{x}=7.5$, and the center-to-center spacing among micropiles $S=S^{\prime}=3 \mathrm{D}$. Micropiles are modeled as 3D elastic pile elements as above, and a rough micropile surface is assumed, of stiffness $k_{s}=k_{n}=1.3 \times$ $10^{11} \mathrm{~Pa}$, cohesive strength $C_{s}=1.5 \times 10^{10} \mathrm{~Pa}$ and $C_{n}=$ $1.0 \times 10^{4} \mathrm{~Pa}$, and friction angle $\varphi_{s}=\varphi_{n}=20^{\circ}$.

When the slope is reinforced with micropiles, the factor of safety is 1.45 using an associated flow rule with the proposed method. The approximate critical slip surface can be visually observed from the shear strain contour as shown in Figure 8.

The design of micropiles particular for slope stabilization usually dictates the need for groups of closely spaced piles. With conventional micropiles, there is a compromise to be resolved between the desire to select a close micropile spacing and, on the other hand, the need to maintain a certain minimum interpile spacing so as to avoid the group effect necessitating a reduction in the nominal capacity of each pile. On the basis of the experimental studies conducted by
Lieng [25], for $S / D$ values greater than 3, which are generally used in micropile design practice, the reduction account for the group effect is negligible. However, if the direction of loading is in line with the interaction of micropiles, the interaction is not a simple function but depends greatly on the relative positions of the micropiles. Such effects have not been examined in this paper.

Special analysis was performed to verify the micropile spacing that can generate sufficient soil arching and achieve better deformation compatibility between the micropiles and the enclosed soil mass. The index $\delta$ was defined with a dimensionless ration of interpile ground displacement, $u_{s}$, to the maximum displacement of the micropile heads $u_{\mathrm{pi}}$ at collapse. If this ratio is maintained between 1 and 2 (at most) micropiles and the inner-micropile soil are displaced by nearly the same amount and micropiles could be considered to be effective in terms of arching.

Figure 9 shows the relationship of the index $\delta$ of the system for different depth of the slope in Figure 8. The $\delta$ values range between 1.0 and 1.1 along the depth, which demonstrated that a highly composite system could be formed with $S=S^{\prime}=3 \mathrm{D}$ in this study. Micropiles and the micropile enclosed soil mass behave as a coherent body during the reinforced slope failure.

\section{Results and Discussions}

To simplify the representations of results, the factor of safety of micropile reinforced slopes is defined with a nondimensional parameter called improvement factor $\left(I_{f}\right)$ given by

$$
I_{f}=\frac{\mathrm{FS}_{\text {reinforced }}}{\mathrm{FS}_{\text {unreinforced }}},
$$

where $\mathrm{FS}_{\text {reinforced }}$ and $\mathrm{FS}_{\text {unreinforced }}$ are factors of safety for reinforced and unreinforced slopes, respectively.

4.1. Effect of Micropile Position. The position of the pile is very important and its effect has been discussed by several authors $[18,19]$, who came to the similar conclusion that the improvement of the safety factor will be largest when the piles are installed in the middle of the slopes. However, the comparative tests between micropiles and conventional antisliding piles conducted by Sun et al. [8] showed that micropiles were totally different from antisliding pile with regard to the loading mechanism. With larger flexural rigidity, conventional piles suffered inclination deformation result from compression fracture of soil behind pile. With small flexural rigidity, micropiles suffered flexible deformation, which also made the plastic zone of soil among micropiles cross and overlap, so the larger lateral displacement occurred at the sliding surface and on the top of the micropile. Therefore, the conclusion for conventional piles cannot be easily adapted to micropiles.

The micropile system positions in the slope are indicated with a dimensionless ratio of the horizontal distance between the slope toe and the micropile positions, $L_{x}$, to the horizontal distance between the slope toe and slope shoulder, $L$, as shown in Figure 6. The influence of the system positions 


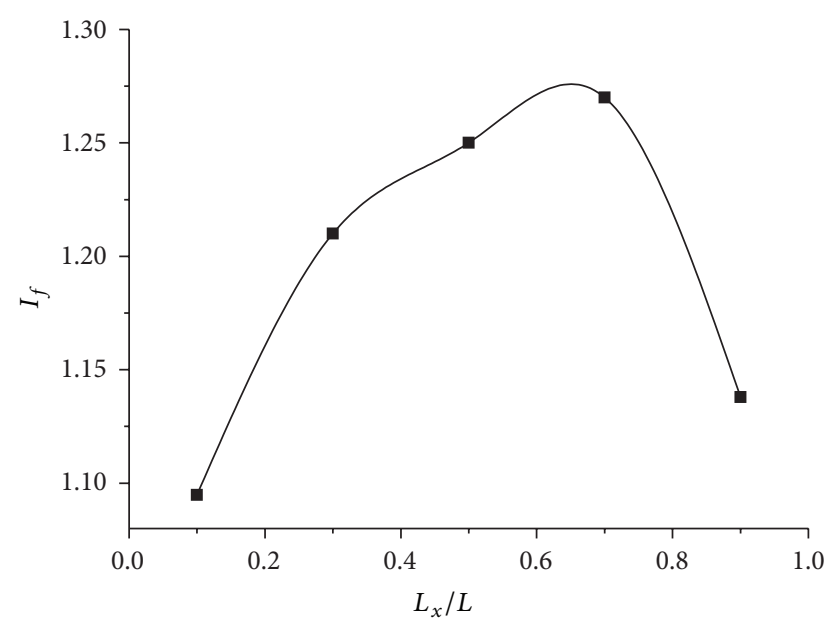

FIGURE 10: Effects of system positions on slope stability.

on the safety factor of the homogeneous slope is shown in Figure 10. The numerical results, obtained with the proposed method, show that the improvement of the safety factor of slopes reinforced with micropiles is largest when the system is installed in the middle-upper part of the slope. In the present study, the factor of safety will be the optimal solution when the system position is $L_{x} / L=0.7$. Therefore, the system in slope stabilization should be placed slightly closer to the top of the slope for the largest safety factor. The reason for this is that when the system is placed in the middle-upper part of the slopes, the shear strength of the soil-micropile interface is sufficiently mobilized.

The critical slip surfaces and the factors of safety for different system positions are shown in Figure 11. The approximate critical slip surface can be visually observed from the shear strain contour. When $L_{x} / L=0.1$, a clear single critical slip surface is shown in Figure 11(a), which is nearly the same as the critical slip surface for unreinforced slope. This means that micropiles placed in the toe of slope has little effect on the overall stability, and the slope occurs sliding over the pile head. When $L_{x} / L=0.3$ (Figure 11(b)), the critical slip surface is divided into two parts due to the presence of the micropile, but the shear strain in the upper part is mobilized at the limit state. This means that the overall safety factor of the slope will be controlled by the upper part of the critical slip surface. When $L_{x} / L$ increases from 0.5 to 0.7 (Figures 8 and 11(c)), the critical slip surface is also divided into two parts, but the two parts of the critical slip surfaces get deeper due to the shear strain mobilization along the vertical direction at the interface between the micropile and soil. A clear shear strain mobilization in the vertical direction is found at the micropile location. When $L_{x} / L=0.9$ (Figure 11(d)), with the micropile located in the vicinity of the crest of the slope, the lower part of slope away from the micropiles occurs overall failure. And, it can be seen that the critical slip surface is clearly one single critical slip surface, but the critical slip surface is shallower than that with no micropile.

It is obvious that the critical slip surface can change due to the addition of the micropile, which demonstrates the coupled effect exists between micropiles and slope system. Therefore, the uncoupled analysis, which can only consider a fixed failure surface should be limited in its application in homogeneous slope stabilization with micropiles.

4.2. Effect of Micropile Embedment. It should be noted that micropile embedment influences the ultimate resistance force offered by the system, thus the depth of micropile embedment will have a great influence on the stability of the micropiledslope. The critical embedment depth of micropile will be investigated in the present study.

The length of micropile above the critical slip surface, $H_{a}$ and below the critical slip surface, $H_{b}$, can be obtained approximately from Figure 7 and based on the micropile location as shown in Figure 8, respectively. The relative depth of micropile embedment is indicated with a dimensionless ratio of the $H_{b}$ and $H_{a}$.

When micropile system is installed with the horizontal distance between the slope toe and the micropile position, $L_{x}$ of $7.5 \mathrm{~m}$, the effect of micropile embedment on safety factor is shown in Figure 12. As expected, the safety factor increases significantly as the depth of micropile embedment increases. It is noticed that the safety factor of the reinforced slope increases rapidly when the relative depth of micropile embedment $H_{b} / H_{a}$ increases from 1.0 to 2.0. But, the safety factor increases slightly when the relative depth of micropile embedment $H_{b} / H_{a}$ increases beyond 2.0. This implies that there exists a critical embedment depth $H_{b}$, which is of the order of $2.0 \mathrm{H}_{a}$ in this case. This is explained by the fact that the embedment is enough to provide adequate fixity conditions. Therefore, for homogeneous slope stabilizing design, the micropile length in the stable layer should not exceed the critical embedment length of 2 times the length of micropile above the critical slip surface. But, it is noted that the strength of the stable layer influences the critical embedment depth, and the increase of strength of the stable layer will unavoidably be associated with a decreased critical embedment depth.

It is clear from Figure 13 that micropile system behaves different from the embedment length. Snapshots of deformed mesh are compared in Figure 13 for the four extremes: $H_{b} / H_{a}=1.0,1.5,2.0$, and 2.5 . The deformed mesh gives a rather diffuse indication of the failure mechanism. For the small embedment length (Figure 13(d)), the system behaves rigid and its response resembles that of a caisson. The deformation of the system is dominated by rigid-body rotation without substantial flexural distortion. This finding is consistent with Poulos's [26] description of the short conventional pile mode of failure, which involves mobilization of the stable soil strength and failure of the soil underneath the pile. Therefore, the micropile capacity is not adequately exploited in this case, and such a design would not be economical. To utilize the full micropile system capacity, a larger embedment depth is required, so does the ability of the stable layer to provide fixity conditions. As the length of micropiles embedment increases, micropiles flexure rather than rotation becomes increasingly prevalent as vividly portrayed in Figures 13(a) and 13(b). 


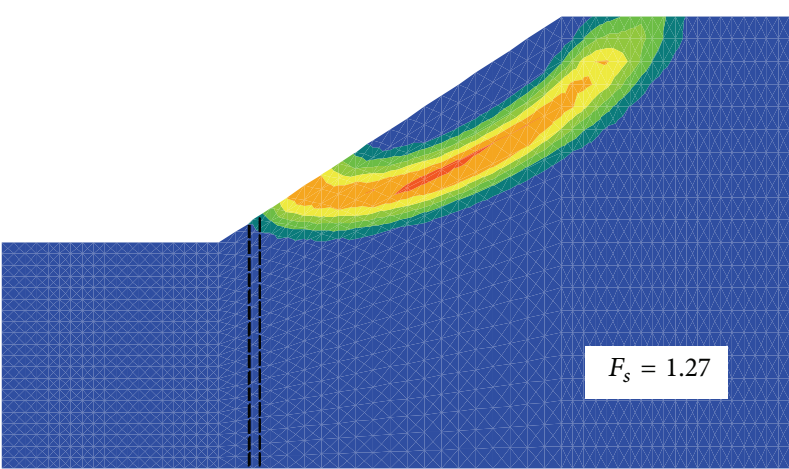

(a) $L_{x} / L=0.1$

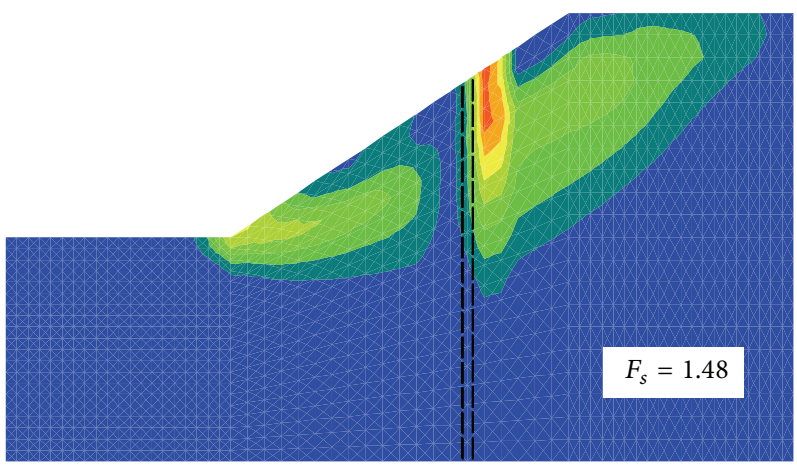

(c) $L_{x} / L=0.7$

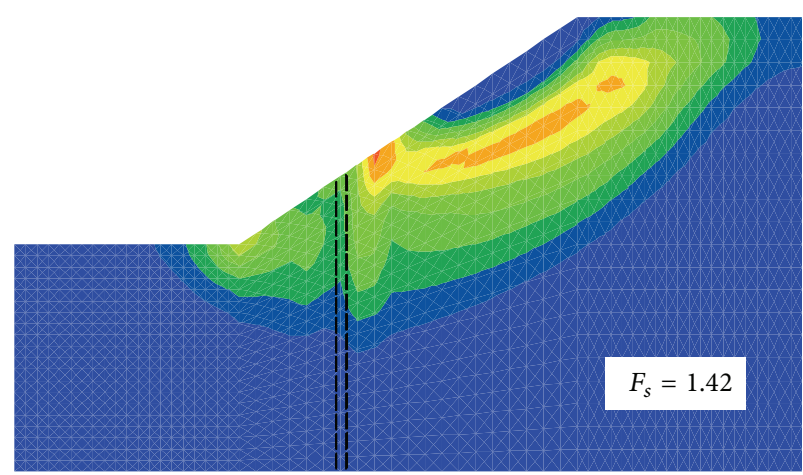

(b) $L_{x} / L=0.3$

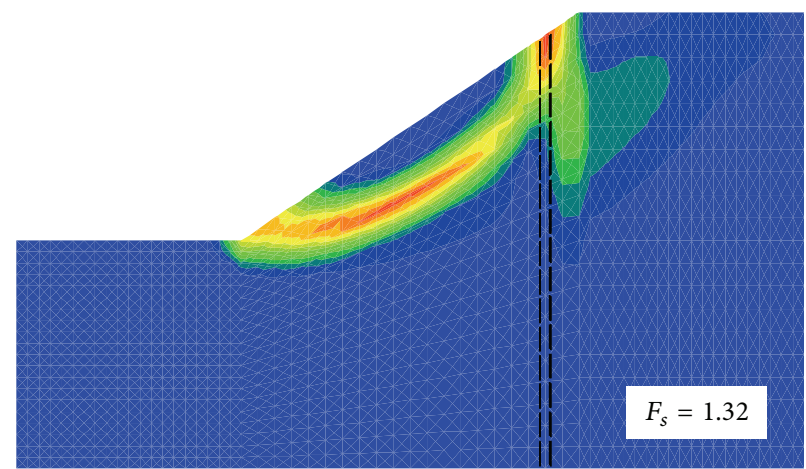

(d) $L_{x} / L=0.9$

FIGURE 11: Effects of system positions on failure mode of slope.

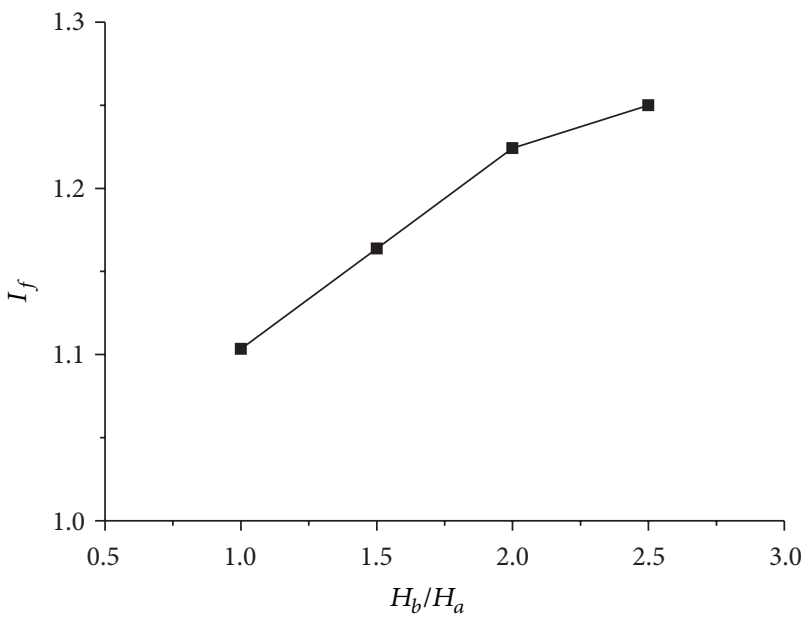

FIGURE 12: Effects of micropiles embedment length on slope stability.

4.3. Effect of Truncation of Micropiles. The truncation of micropiles likely increases the capacity of the micropile system (Figure 14), because the moment development in a truncated micropile is reduced due to the shortened moment arm on which the load acts. But, truncation of micropiles will decrease the safety factor of reinforced slope. Therefore, the largest truncation length of a micropile, beyond which the slope may occur sliding over the pile head, is very meaningful and important for the detailed design of a micropile system supported slope. In this paper, the relative length of micropile truncation is investigated with a dimensionless ratio of the length of micropile truncation, $C_{x}$, to the length of micropile above the potential slip surface, $H_{a}$ as shown in Figure 14 .

The effect of the truncation of micropiles on the safety factor of the slope stabilized with micropiles is shown in Figure 15. As expected, the rate of decrease in the safety factor increases with increasing the truncation length of micropiles. It can be seen that the safety factor of the reinforced slope decreases slightly when the relative length of micropiles truncation $C_{x} / H_{a}$ increases from 0 to $1 / 4$. However, the safety factor of the reinforced slope decreases rapidly when the relative length of micropiles truncation $C_{x} / H_{a}$ increases above $1 / 4$. This implies that there exists the largest truncation length of micropiles, which is of the order of $1 / 4 H_{a}$ in this case.

The differences in the safety factor between different truncation lengths conditions can be explained by the shearing force $Q$ in the micropiles at collapse, as shown in Figure 16. The shearing force is positive when its direction is identical to that of the sliding of the slope, that is, opposite to the $x$ direction in Figure 6.

The lateral shearing force along the $x$-direction in the micropile reaches the first extreme point at a critical depth, which can be regarded as the level of the slip surface according to results of Cai and Ugai [19] and Won et al. [16]. It can be seen that the shearing force in the micropiles at 


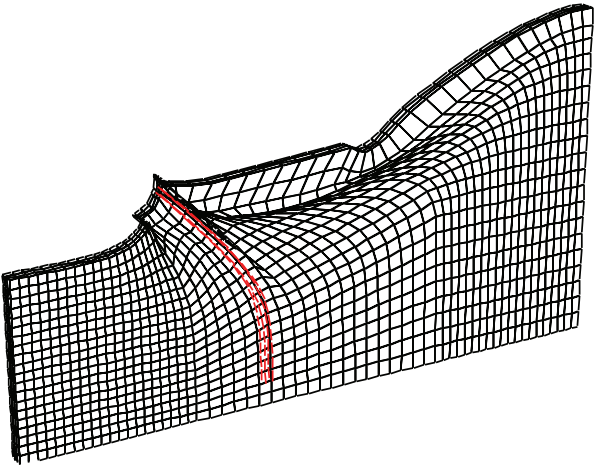

(a)

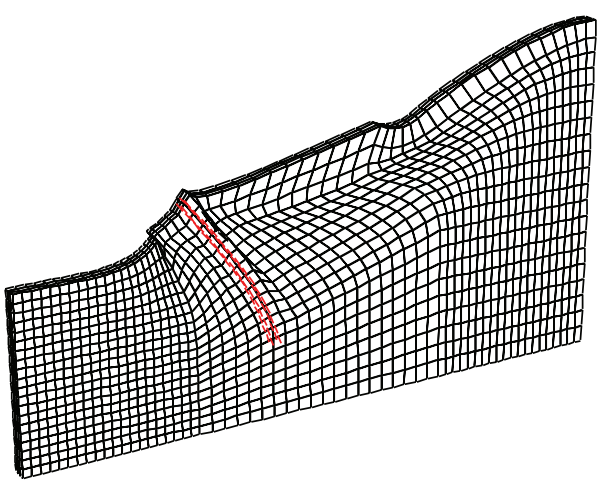

(c)

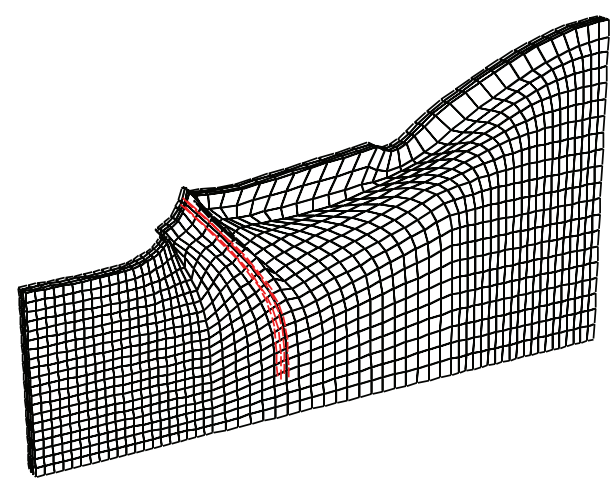

(b)

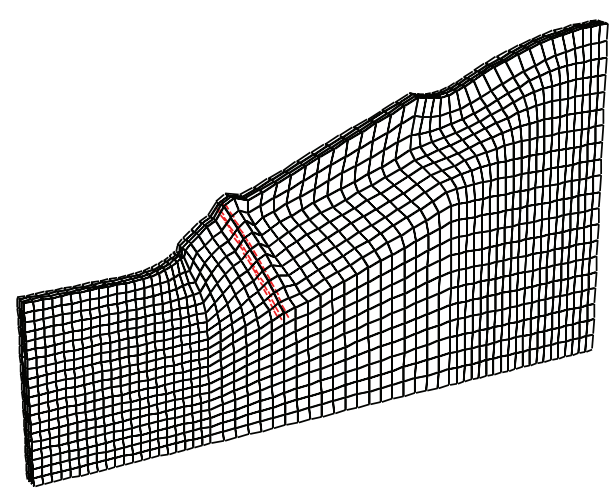

(d)

FIGURE 13: Deformation of reinforced slopes with micropiles.

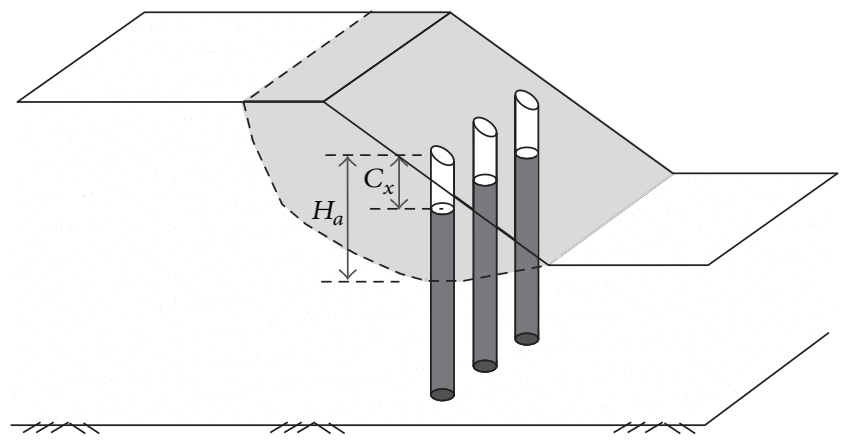

FIGURE 14: Truncation of piles embedded within a slope.

the potential slip surface decreases slightly when the relative length of micropiles truncation $C_{x} / H_{a}$ increases from $1 / 8$ to $1 / 4$, but it decreases rapidly when $C_{x} / H_{a}$ increases beyond $1 / 4$. It is noticed that the shearing force in the micropiles at the potential slip surface is identical to the resisting reaction force to the sliding body. Therefore, the larger the shearing force in the micropile at the potential slip surface, the larger the reaction force to the sliding body supplied by the micropile, and the higher the safety factor of the slope reinforced with micropiles. This conclusion agrees well with the above results of safety factor.

Figure 16 also shows that the maximum bending moment occurs below the potential slip surface for the micropile. The

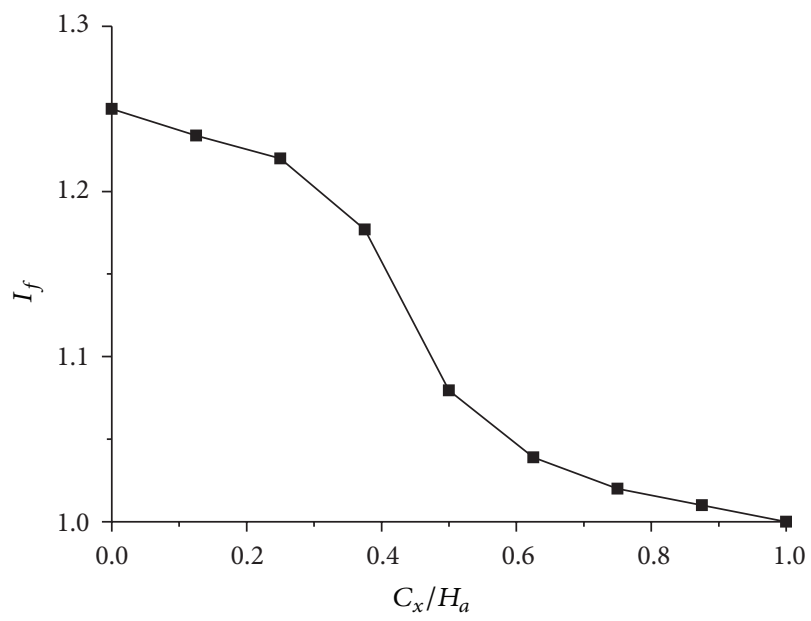

FIGURE 15: Effect of truncation of micropiles on slope stability.

value and depth of the maximum bending moment decrease with increasing the truncation length of micropile. Because it is more possible for the micropile to be yielded by the bending moment than by the shearing force, this benefit will be particularly important for the slope reinforced with micropiles. For truncated micropiles, the portion of borehole could be filled with surrounding soil and compacted in the standard procedure for lesser consumption of reinforcing steel bar. 


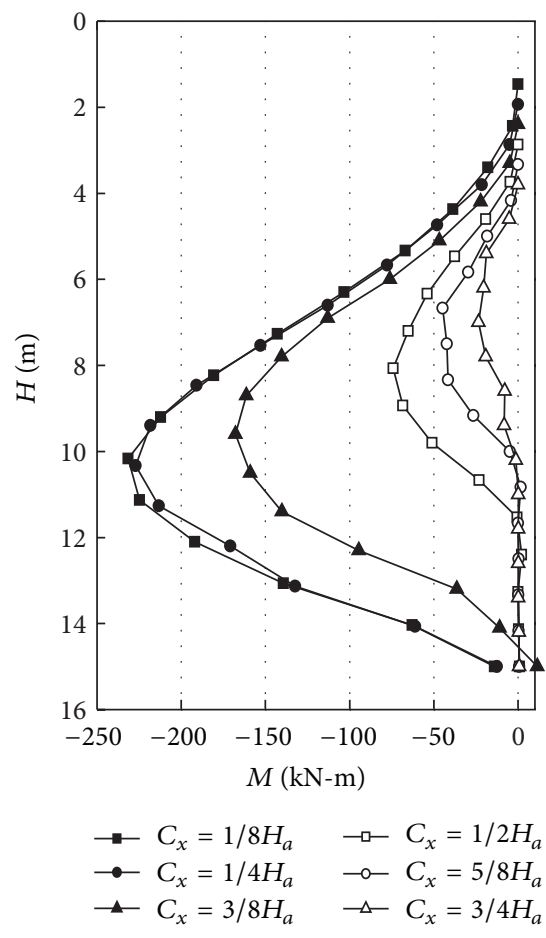

(a)

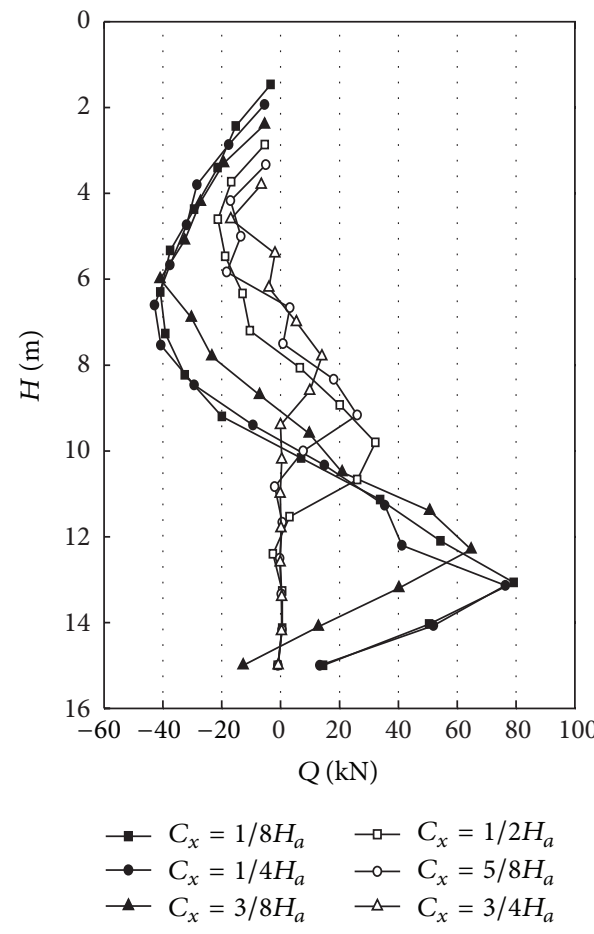

(b)

FIgURE 16: Micropile behavior characteristics.

\section{Conclusions}

A simple nonlinear method has been proposed to analyze the stability of a homogeneous slope reinforced with micropiles. This method is based on shear strength reduction technique, in which the soil behavior is described using the nonassociated Mohr-Coulomb criterion and micropiles are modeled as 3D pile elements.

The reliability of the proposed three-dimensional model has been tested using an example from Won et al. [16] and Cai and Ugai [19] and Wei and Cheng [18]. The value of the factor of safety of the nonreinforced slope is equal to 1.16, which is close to the Cai and Ugai's results with safety factors of 1.14 and 1.13 for finite element and the Bishop's simplified method, respectively. It was found that micropiles could improve significantly the stability of the slope, and the micropile spacing $S=3 \mathrm{D}$ can generate sufficient soil arching and achieve better deformation compatibility between the micropiles and the enclosed soil mass. Micropiles and the micropiles enclosed soil mass behave as a coherent body during the reinforced slope collapse. The authors have proposed an index, $\delta$, to investigate the arching and deformation compatibility of the system.

Our analysis demonstrates that the optimal position of micropile system is located in the middle-upper part of the slopes. Besides, it was found that the position of micropile system plays an important role not only in the calculation of the safety factor, but also in locating the failure surface, which demonstrates the dominating coupled effect exists between micropiles and slope. Therefore, the uncoupled analysis, which can only consider a fixed failure surface, should be limited in its application in homogeneous slope stabilization with micropiles.

The results of this study demonstrate that, to obtain the full micropile system capacity, a larger embedment depth of the micropile is required, so does the ability of the stable layer to provide fixity conditions. The value of safety factor will increase with the increase of embedment depth when the relative depth of micropile embedment $H_{b} / H_{a} \leq$ 2.0. However, the safety factor of reinforced slope reaches almost stable values when $H_{b} / H_{a}>2.0$. Therefore, for the homogeneous slope in this study, the micropile length in the stable layer should not exceed the critical embedment length of 2 times the length of micropile above the critical slip surface. Moreover, it was found that the micropiles flexure rather than rotation becomes increasingly prevalent as the depth of micropiles embedment increases.

It should be note that, truncation of the micropile may improve the capacity of the micropiles system, and the largest truncation length of micropiles is about $1 / 4$ depth of critical slip surface in this study. In practice engineering, the upper boreholes for truncated micropiles could be filled with surrounding soil and compacted in the standard procedure for lesser consumption of reinforcing steel bar.

The current three-dimensional slope stability study is based on a simple homogeneous slope. However, the geometry of real slopes is more complex. For example, a natural slope often has curvature, and irregular surfaces appear in 
open-pit and roadside design. Therefore, further research is required to consider the effect of complex geometries on three-dimensional numerical analysis.

\section{Conflict of Interests}

The authors declare that there is no conflict of interests regarding the publication of this paper.

\section{Acknowledgments}

This work was supported by the Chinese National Science Fund (no. 41002090 and no. 51034005) and the Fundamental Research Funds for the Central Universities (no. 800015T5). They would like to express their gratitude to the editors and reviewers for their constructive and helpful review comments.

\section{References}

[1] F. Lizzi, "Reticulated Root Piles to correct landslides," in Proceedings of the ASCE Convention, Preprint 3370, Chicago, Ill, USA, October 1978.

[2] R. Cantoni, T. Collotta, and V. Ghionna, "A design method for reticulated micropiles structure in sliding slopes," Ground Engineering, vol. 22, no. 4, pp. 41-47, 1989.

[3] S. L. Pearlman, B. D. Campbell, and J. L. Withiam, "Slope stabilization using in-situ earth reinforcement," in Proceedings of the ASCE Conference on Stability and Performance of Slopes and Embankments, vol. 2, Berkeley, Calif, USA, 1992.

[4] J. E. Loehr, J. J. Bowders, J. W. Owen, L. Sommers, and W. Liew, "Slope stabilization with recycled plastic pins," Transportation Research Record, no. 1714, pp. 1-8, 2000.

[5] W. K. Howe, "Micropiles for slope stabilization," in Proceedings of the Biennial Geotechnical Seminar, ASCE, New York, NY, USA, 2000.

[6] M. Esmaeili, M. G. Nik, and F. Khayyer, "Experimental and numerical study of micropiles to reinforce high railway embankments," International Journal of Geomechanics, vol. 13, no. 6, pp. 729-744, 2013.

[7] L. C. Reese, S. T. Wang, and J. L. Fouse, "Use of drilled shafts in stabilizing a slope," in Stability and Performance of Slopes and Embankments II, Geotechnical Special Publication (GSP) no. 31, pp. 1318-1332, 1992.

[8] S.-W. Sun, B.-Z. Zhu, H.-M. Ma, and R.-H. Yang, "Model tests on anti-sliding mechanism of micropile groups and anti-sliding piles," Chinese Journal of Geotechnical Engineering, vol. 31, no. 10, pp. 1564-1570, 2009 (Chinese).

[9] S.-W. Sun, B.-Z. Zhu, and J.-C. Wang, "Design method for stabilization of earth slopes with micropiles," Soils and Foundations, vol. 53, no. 4, pp. 487-497, 2013.

[10] S. Isam, A. Hassan, and S. Mhamed, "3D elastoplastic analysis of the seismic performance of inclined micropiles," Computers and Geotechnics, vol. 39, pp. 1-7, 2012.

[11] O. C. Zienkiewicz, C. Humpheson, and R. W. Lewis, "Associated and non-associated visco-plasticity and plasticity in soil mechanics," Geotechnique, vol. 25, no. 4, pp. 671-689, 1975.

[12] T. Matsui and K. C. San, "Finite element slope stability analysis by shear strength reduction technique," Soils and Foundations, vol. 32, no. 1, pp. 59-70, 1992.
[13] K. Ugai and D. Leshchinsky, "Three-dimensional limit equilibrium and finite element analyses: a comparison of results," Soils and Foundations, vol. 35, no. 4, pp. 1-7, 1995.

[14] E. M. Dawson, W. H. Roth, and A. Drescher, "Slope stability analysis by strength reduction," Geotechnique, vol. 49, no. 6, pp. 835-840, 1999.

[15] D. V. Griffiths and P. A. Lane, "Slope stability analysis by finite elements," Geotechnique, vol. 49, no. 3, pp. 387-403, 1999.

[16] J. Won, K. You, S. Jeong, and S. Kim, "Coupled effects in stability analysis of pile-slope systems," Computers and Geotechnics, vol. 32, no. 4, pp. 304-315, 2005.

[17] H. Lin and P. Cao, "A dimensionless parameter determining slip surfaces in homogeneous slopes," KSCE Journal of Civil Engineering, vol. 18, no. 2, pp. 470-474, 2014.

[18] W. B. Wei and Y. M. Cheng, "Strength reduction analysis for slope reinforced with one row of piles," Computers and Geotechnics, vol. 36, no. 7, pp. 1176-1185, 2009.

[19] F. Cai and K. Ugai, "Numerical analysis of the stability of a slope reinforced with piles," Soils and Foundations, vol. 40, no. 1, pp. 73-84, 2000.

[20] N. Snitbhan and W.-F. Chen, "Elastic-plastic large deformation analysis of soil slopes," Computers and Structures, vol. 9, no. 6, pp. $567-577,1978$.

[21] J. M. Duncan and P. Dunlop, "Slopes in stiff fissured clays and soils," Journal of Soil Mechanics and Foundation Engineering, vol. SM5, pp. 467-492, 1969.

[22] O. C. Zienkiewicz and R. L. Taylor, The Finite Element Method, vol. 1, McGraw-Hill, London, UK, 4th edition, 1989.

[23] L. W. Abramson, T. S. Lee, S. Sharma, and G. M. Boyce, Slope Stability and Stabilization Methods, John Wiley \& Sons, Chichester, UK, 1995.

[24] FLAC3D, Fast Lagrangian Analysis of Continua in 3 Dimensions, Version 3.0, Itasca Consulting Group, Minneapolis, Minn, USA, 2005.

[25] J. T. Lieng, Behavior of laterally loaded piles in sand large scale model tests [Ph.D. thesis], Department of Civil Engineering, Nowegian Institute of Technology, 1988.

[26] H. G. Poulos, "Design of reinforcing piles to increase slope stability," Canadian Geotechnical Journal, vol. 32, no. 5, pp. 808$818,1995$. 


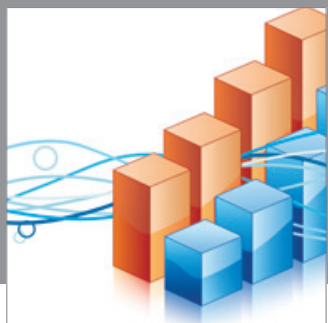

Advances in

Operations Research

mansans

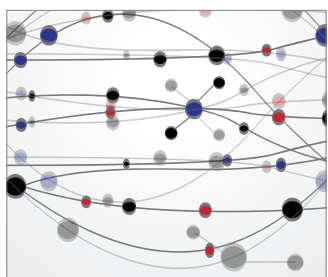

The Scientific World Journal
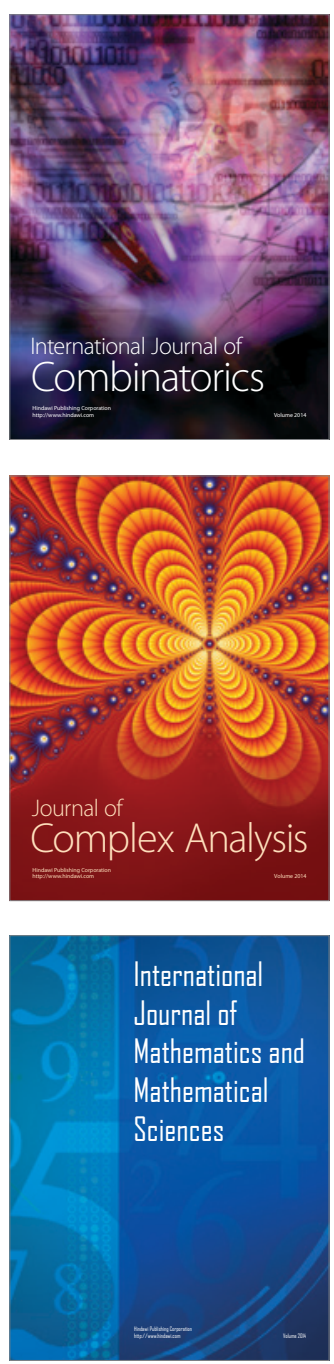
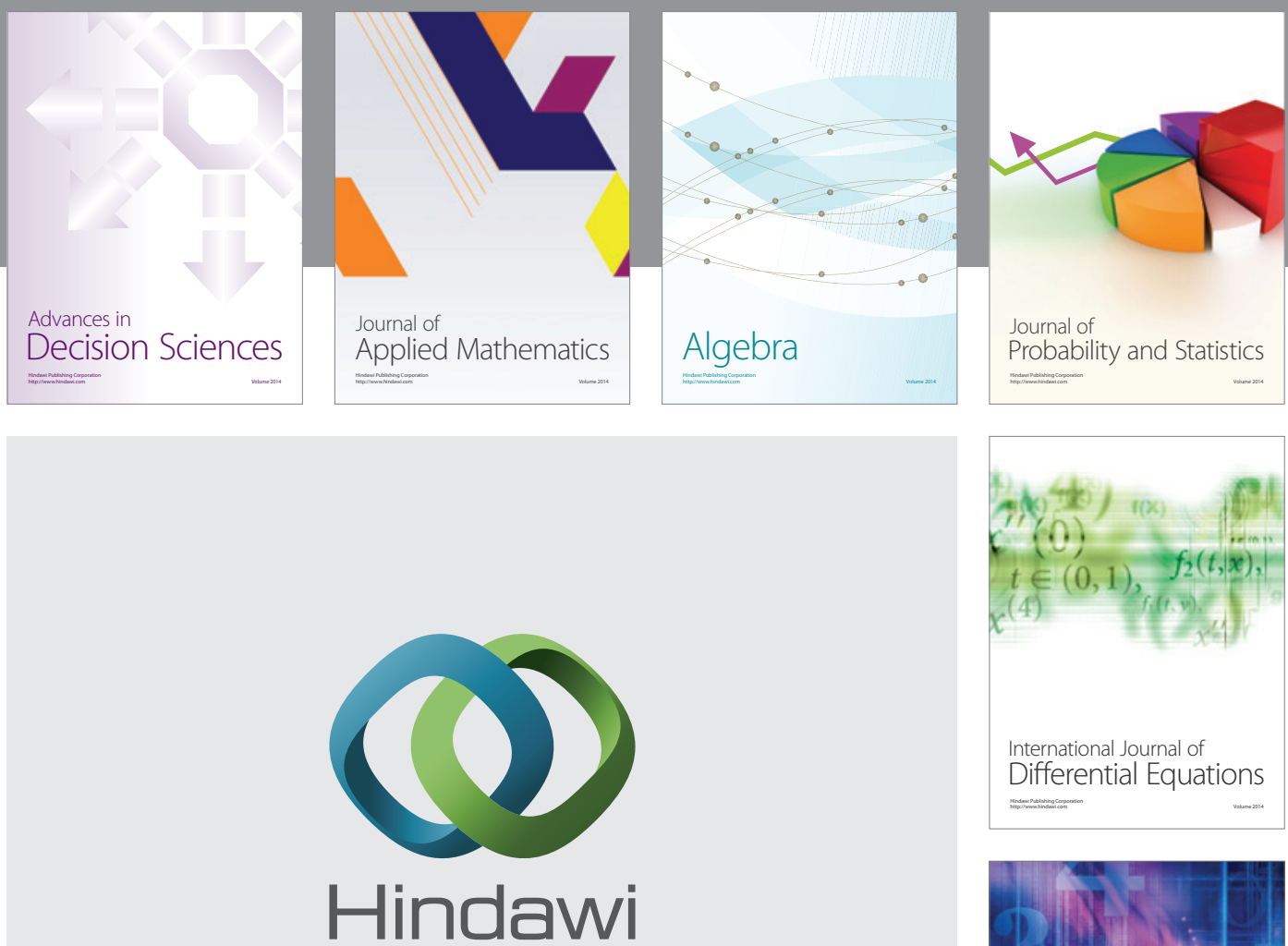

Submit your manuscripts at http://www.hindawi.com
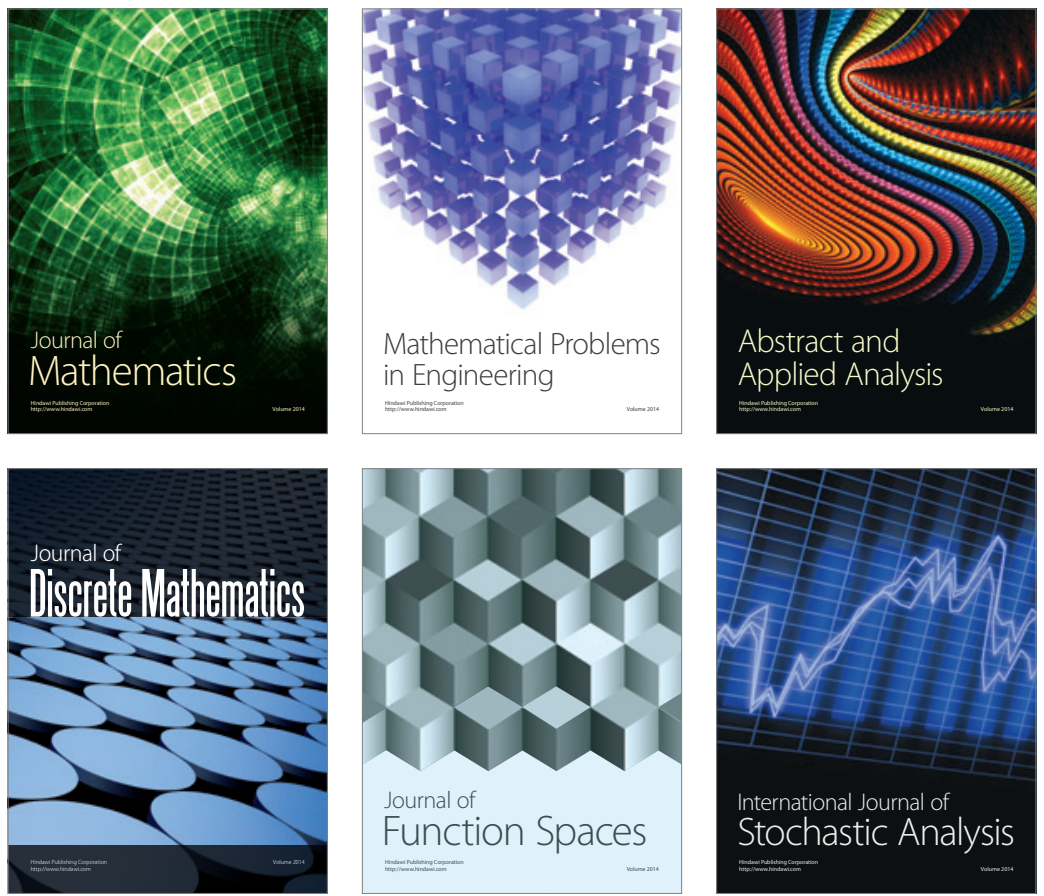

Journal of

Function Spaces

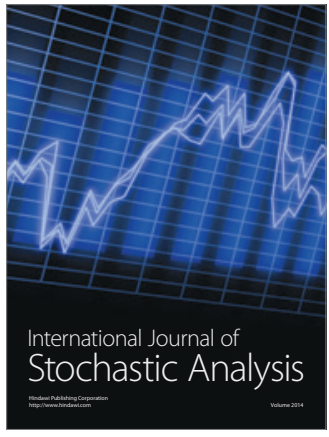

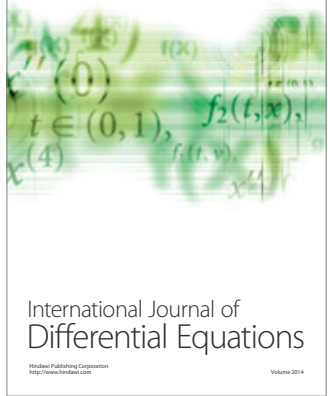
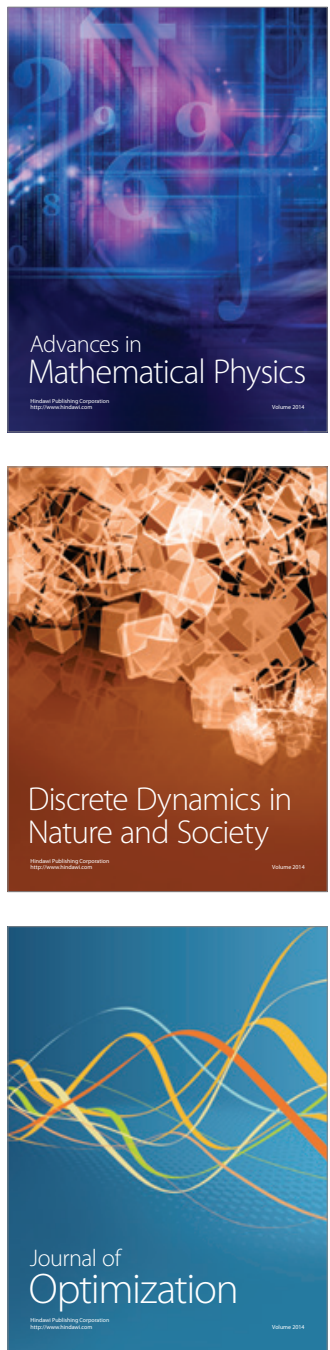